\title{
Crystalline tungsten sulfide thin films by atomic layer deposition
} and mild annealing

\section{Mattinen, Miika}

2019-03

Mattinen , M , Hatanpää , T , King , P J , Meinander , K, Mizohata , K, Jalkanen , P , Räisänen , J , Ritala , M \& Leskelä , M 2019 , ' Crystalline tungsten sulfide thin films by atomic layer deposition and mild annealing ' , Journal of vacuum science \& technology : an official journal of the American Vacuum Society , vol. 37 , no. 2 , 020921 . https://doi.org/10.1116/1.5074153

http://hdl.handle.net/10138/301610

https://doi.org/10.1116/1.5074153

acceptedVersion

Downloaded from Helda, University of Helsinki institutional repository.

This is an electronic reprint of the original article.

This reprint may differ from the original in pagination and typographic detail.

Please cite the original version. 


\section{Crystalline Tungsten Sulfide Thin Films by Atomic Layer Deposition and Mild Annealing}

Running title: Tungsten Sulfide Thin Films

Running Authors: Mattinen et al.

Miika Mattinen, a) Timo Hatanpää, Peter J. King

Department of Chemistry, University of Helsinki, P.O. Box 55, FI-00014, Finland

Kristoffer Meinander, Kenichiro Mizohata, Pasi Jalkanen, Jyrki Räisänen

Division of Materials Physics, Department of Physics, University of Helsinki, P.O. Box 43, FI00014, Finland

\section{Mikko Ritala, b) Markku Leskelä}

Department of Chemistry, University of Helsinki, P.O. Box 55, FI-00014, Finland

a) Electronic mail: miika.mattinen@helsinki.fi

b) Electronic mail: mikko.ritala@helsinki.fi

Tungsten disulfide $\left(\mathrm{WS}_{2}\right)$ is a semiconducting $2 \mathrm{D}$ material, which is gaining increasing attention in the wake of graphene and $\mathrm{MoS}_{2}$ owing to its exciting properties and promising performance in a multitude of applications. Herein, we deposited $\mathrm{WS}_{\mathrm{x}}$ thin films by atomic layer deposition (ALD) using $\mathrm{W}_{2}\left(\mathrm{NMe}_{2}\right)_{6}$ and $\mathrm{H}_{2} \mathrm{~S}$ as precursors. The films deposited at $150{ }^{\circ} \mathrm{C}$ were amorphous and sulfur deficient. The amorphous films crystallized as $\mathrm{WS}_{2}$ by mild post-deposition annealing in $\mathrm{H}_{2} \mathrm{~S} / \mathrm{N}_{2}$ atmosphere at $400{ }^{\circ} \mathrm{C}$. Detailed structural characterization using Raman spectroscopy, X-ray diffraction, and transmission electron microscopy revealed that the annealed films consisted of small $(<10 \mathrm{~nm})$ disordered grains. Our approach enables deposition of continuous and smooth $\mathrm{WS}_{2}$ films down to a thickness of a few monolayers while retaining a low thermal budget compatible with potential applications in electronics as well as energy production and storage, for example. 


\section{INTRODUCTION}

The remarkable demonstration of producing graphene, a stable, one-atom-thick layer of carbon by simply exfoliating a bulk crystal with adhesive tape in $2004^{1}$ led to a rapid increase in studies of a variety of two-dimensional (2D) materials and their evaluation for applications including electronics, optoelectronics, catalysis, and energy storage..$^{2-7}$ The huge interest in 2D materials stems from their unique properties that originate from their layered crystal structures as well as from their stability in ultrathin form of a few to only one atom(s) thick. ${ }^{8,9}$ In particular, during the last few years intense attention has been given to the broad and versatile group of transition metal dichalcogenides (TMDCs), which includes metals and semimetals as well as semiconductors with band gaps varying from less than 1 to nearly 3 $\mathrm{eV} .^{2,3,10,11}$ The properties of TMDCs can be further tailored by controlling their thickness, ${ }^{12,13}$ surface functionalization, ${ }^{14}$ strain,,${ }^{15,16}$ doping and alloying, ${ }^{17,18}$ and creating heterostructures with other 2D materials..$^{8,17,19}$

Tungsten disulfide $\left(\mathrm{WS}_{2}\right)$ is a semiconducting TMDC, which has an indirect band gap of 1.3$1.4 \mathrm{eV}$ in bulk in the common $2 \mathrm{H}$ and $3 \mathrm{R}$ phases, which have trigonal prismatic coordination around tungsten and only differ in the stacking of the $\mathrm{WS}_{2}$ layers. ${ }^{3,20}$ The band gap of $\mathrm{WS}_{2}$ increases with decreasing thickness and, intriguingly, becomes direct at monolayer thickness with a magnitude of approximately $2.0 \mathrm{eV}$ for the optical band gap. ${ }^{13,21}$ The electronic structures of $2 \mathrm{H}$ and $3 \mathrm{R} \mathrm{WS}_{2}$ make them suitable for many semiconductor applications such as field-effect transistors, ${ }^{22,23}$ photodetectors, ${ }^{6,24}$ and photocatalysis, ${ }^{25,26}$ while other promising applications, such as electrocatalysis ${ }^{27}$ and supercapacitors ${ }^{28}$ benefit from the increased electrical conductivity of the metastable, metallic 1T-phase of $\mathrm{WS}_{2}$, which has octahedral coordination around tungsten.

For many of the aforementioned applications, $\mathrm{WS}_{2}$ should be deposited as continuous films of accurately controlled thickness on large or nanostructured substrates, preferably at low 
temperatures. Gas phase methods such as chemical vapor deposition (CVD) and atomic layer deposition (ALD) hold the greatest promise in meeting these requirements. Excluding the top-down exfoliation methods of bulk crystals, CVD is currently the main method used to deposit high-quality crystals and films of $\mathrm{WS}_{2}$ and other TMDCs. ${ }^{3,29}$ However, these CVD processes require high deposition temperatures of $550-750,700-1000$ or $700-1100{ }^{\circ} \mathrm{C}$ when using $\mathrm{W}(\mathrm{CO})_{6},{ }^{23,30} \mathrm{WCl}_{6},{ }^{31,32}$ or the poorly volatile $\mathrm{WO}_{3}{ }^{33-35}$ as the tungsten precursor, respectively. Furthermore, large-area continuous $\mathrm{WS}_{2}$ films are rarely achieved using these processes. Another bottom-up approach to produce $\mathrm{WS}_{2}$ is sulfurization of $\mathrm{W}$ or $\mathrm{WO}_{3}$ films deposited by evaporation, sputtering, or ALD, for example. Although sulfurization can produce uniform, continuous films on large substrates, the films typically have limited grain size ranging from a few to a few tens of nm despite the use of high temperatures, typically $750-1000{ }^{\circ} \mathrm{C} .^{3,36,37}$

ALD, which is often considered to be an advanced variant of CVD, is a gas-phase thin film deposition technique that is based on self-limiting surface reactions. ${ }^{38-40}$ Contrary to CVD, gas phase reactions and self-decomposition of precursors are avoided in ALD by pulsing the precursors alternately (separated by purge steps) and by using deposition temperatures below the decomposition temperatures of the precursors, respectively. Advantages of ALD include excellent reproducibility and facile thickness control achieved by changing the number of ALD cycles as well as extreme thickness uniformity and conformality. ALD films are usually of high quality despite the use of relatively low deposition temperatures, often 100 to $400{ }^{\circ} \mathrm{C}$. Furthermore, ALD is also easily scalable for industrial use..$^{40,41}$

In recent years, ALD has been increasingly studied for the deposition of various TMDCs, although so far most studies have focused on $\mathrm{MoS}_{2} \cdot{ }^{42}$ On the contrary, only a few processes have been demonstrated for $\mathrm{WS}_{2} . \mathrm{WF}_{6}$ does not enable film growth with $\mathrm{H}_{2} \mathrm{~S}$ unless a $\mathrm{H}_{2}$ 
plasma pulse $\mathrm{e}^{43-46}$ is added before the $\mathrm{H}_{2} \mathrm{~S}$ pulse or either a $\mathrm{ZnS}$ substrate or a $\mathrm{ZnEt}_{2}$ pulse $\mathrm{p}^{47-49}$ is applied. $\mathrm{W}(\mathrm{CO})_{6}$ can be used to deposit amorphous or nanocrystalline $\mathrm{WS}_{2}$ films with either $\mathrm{H}_{2} \mathrm{~S}^{50,51}$ or $\mathrm{H}_{2} \mathrm{~S}$ plasma ${ }^{52}$ reactants. The use of $\mathrm{WCl}_{5}$ with $\mathrm{H}_{2} \mathrm{~S}$ has also been claimed, but very limited information is available about the precursor as well as the process and its ALD characteristics. ${ }^{53}$ Furthermore, in many cases the ALD WS 2 films have been tens to hundreds of $\mathrm{nm}$ in thickness - indeed, in addition to the $\mathrm{WCl}_{5}+\mathrm{H}_{2} \mathrm{~S}$ process, ultrathin $(<10$ $\mathrm{nm}$ ) films have only been deposited by the $\mathrm{W}(\mathrm{CO})_{6}+\mathrm{H}_{2} \mathrm{~S}$ plasma ${ }^{52}$ and $\mathrm{WF}_{6}+\mathrm{H}_{2}$ plasma $+\mathrm{H}_{2} \mathrm{~S}^{43-46}$ PEALD processes operated at 350 and $250-450{ }^{\circ} \mathrm{C}$, respectively. Herein, we report a low-temperature ALD process for the deposition of tungsten sulfide thin films. Using $\mathrm{W}_{2}\left(\mathrm{NMe}_{2}\right)_{6}$ and $\mathrm{H}_{2} \mathrm{~S}$ as the precursors, amorphous films are deposited at $150{ }^{\circ} \mathrm{C}$. A $400{ }^{\circ} \mathrm{C}$ post-deposition annealing step in $\mathrm{H}_{2} \mathrm{~S} / \mathrm{N}_{2}$ atmosphere is added to crystallize the films as semiconducting $\mathrm{WS}_{2}$. We show that the process can be used to produce crystalline ultrathin $(<10 \mathrm{~nm}) \mathrm{WS}_{2}$ films while maintaining a low thermal budget. 


\section{EXPERIMENTAL}

Tungsten sulfide thin films were deposited in a commercial, hot wall, cross-flow F120 ALD reactor ${ }^{54}$ operated at approximately 5 mbar. Nitrogen $\left(\mathrm{N}_{2}\right.$, AGA, 99.999\%) served as both the carrier and the purge gas. The substrates were soda lime glass and silicon (100) with size up to $5 \times 5 \mathrm{~cm} 2$, the latter covered by either a native oxide or a 90 $\mathrm{nm}$ thermal $\mathrm{SiO}_{2}$ layer. The glass substrates were cleaned using successive ultrasonic baths of alkaline ultrasonic cleaning solution, tap water, ethanol, and de-ionized water. The silicon substrates were blown clean of particles using pressurized nitrogen. The native silicon oxide layer was not removed.

The dimeric tungsten(III) amide $\mathrm{W}_{2}\left(\mathrm{NMe}_{2}\right)_{6}$ was synthesized following a published procedure ${ }^{55}$ with slight modifications (yield 69.5\%). $\mathrm{W}_{2}\left(\mathrm{NMe}_{2}\right)_{6}$ was heated to $120^{\circ} \mathrm{C}$ in an open glass boat inside the ALD reactor and pulsed by inert gas valving. $\mathrm{H}_{2} \mathrm{~S}$ (AGA, 99.5\%) was fed into the reactor at a flow rate of approximately $14 \mathrm{sccm}$ through a mass flow meter and a needle valve. $\mathrm{H}_{2} \mathrm{~S}$ was pulsed using solenoid valves. For most experiments, excluding the initial depositions of thicker films using 500 cycles, $\mathrm{N}_{2}$ and $\mathrm{H}_{2} \mathrm{~S}$ were further purified using SAES Microtorr MC1-902F and MC1-302F gas purifiers, respectively.

Post-deposition annealing treatments were done for selected films inside the F120 ALD reactor under a flowing atmosphere of $\mathrm{N}_{2}(400 \mathrm{sccm}$, approximately 5 mbar) mixed with $\mathrm{H}_{2} \mathrm{~S}(14 \mathrm{sccm})$ for $1 \mathrm{~h}$ at 300 to $500{ }^{\circ} \mathrm{C}$. Both gases were fed through gas purifiers as described above.

Thermogravimetric analysis (TGA) of $\mathrm{W}_{2}\left(\mathrm{NMe}_{2}\right)_{6}$ was performed under atmospheric pressure of $\mathrm{N}_{2}$ using a Mettler Toledo STARe system equipped with a 
TGA850 thermobalance. The heating rate was $10{ }^{\circ} \mathrm{C} / \mathrm{min}$ and the sample size was approximately $10 \mathrm{mg}$.

Film thicknesses were measured by energy-dispersive X-ray spectroscopy (EDS, Oxford INCA connected to a Hitachi S-4800 SEM) and X-ray reflectivity (XRR, Rigaku Smartlab or PANalytical X'Pert Pro). EDS thicknesses were calculated from W L $\alpha$ and S $\mathrm{K} \alpha \mathrm{X}$-ray lines using the GMRFilm software, ${ }^{56}$ assuming $\mathrm{WS}_{2}$ bulk density of $7.6 \mathrm{~g} / \mathrm{cm}^{3} \cdot{ }^{57} \mathrm{EDS}$ and XRR also provided information on the $\mathrm{S} / \mathrm{W}$ atomic ratio and the film density, respectively.

Film morphology and roughness were studied by atomic force microscopy (AFM, Veeco Multimode V). AFM imaging was performed in ambient air in tapping mode using silicon probes with a tip radius of less than $10 \mathrm{~nm}$ (Bruker). The images were flattened to remove artefacts caused by sample tilt and scanner nonlinearity. Film roughness was calculated as a root mean square value $\left(R_{q}\right)$ from $2 \times 2 \mu \mathrm{m}^{2}$ images.

Film crystallinity was examined by X-ray diffraction (XRD, Rigaku Smartlab) using $\mathrm{Cu} \mathrm{K \alpha}(\lambda=1.54 \AA) \mathrm{X}$-ray beam in grazing incidence (incident angle of $1^{\circ}$ ) geometry as well as by Raman spectroscopy in backscattering geometry using a confocal Raman microscope (NT-MDT Ntegra) with a 100× objective and a $532 \mathrm{~nm}$ laser.

The composition of the surface layers was analyzed by X-ray photoelectron spectroscopy (XPS), using an Argus Spectrometer (Omicron NanoTechnology GmbH) operating at a pass energy of $20 \mathrm{eV}$. Samples were illuminated with X-rays emitted from a standard $\mathrm{Mg}$ source ( $\mathrm{K} \alpha$ line) at a photon energy of $1253.6 \mathrm{eV}$. No sputtering was performed on the samples. Binding energies were calibrated using the $\mathrm{C} 1 \mathrm{~s}$ peak $(284.8$ eV) of ambient hydrocarbons, and peak fitting was done using the CasaXPS software. 
Film composition averaged over the film thickness was analyzed by time-of-flight elastic recoil detection analysis (ToF-ERDA) using a $50 \mathrm{MeV}{ }^{79} \mathrm{Br}^{7+}$ ion beam. The incident and scattering angles were 16 and 40 degrees, respectively.

Cross-sectional high-angle annular dark-field scanning transmission electron microscopy (HAADF-STEM) imaging was performed using a Hitachi HD2700 aberration corrected microscope at EAG Laboratories. The TEM sample was prepared by lift-out method using a focused ion beam instrument. 


\section{RESULTS AND DISCUSSION}

\section{A. Film deposition and characterization of as-deposited films}

We deposited tungsten sulfide thin films by ALD using a dimeric tungsten amide complex hexakis(dimethylamido)ditungsten(III) $\left[\mathrm{W}_{2}\left(\mathrm{NMe}_{2}\right)_{6}\right]$ and hydrogen sulfide $\left(\mathrm{H}_{2} \mathrm{~S}\right)$ as precursors. TGA of $\mathrm{W}_{2}\left(\mathrm{NMe}_{2}\right)_{6}$ confirmed its volatility, but the residual mass of $11.8 \%$, although much below the theoretical tungsten content of 58.2 mass- $\%$, suggests that thermal decomposition started to occur below $300{ }^{\circ} \mathrm{C}$ (Fig. 1). $\mathrm{W}_{2}\left(\mathrm{NMe}_{2}\right)_{6}$ was heated to $120^{\circ} \mathrm{C}$ for the film deposition experiments. Saturation of the growth rate, as is characteristic to ALD, was reached at $150{ }^{\circ} \mathrm{C}$ using $\mathrm{W}_{2}\left(\mathrm{NMe}_{2}\right)_{6}$ and $\mathrm{H}_{2} \mathrm{~S}$ pulses of at least 0.5 and $2.0 \mathrm{~s}$, respectively (Fig. 2a,b). The growth rate determined by EDS was approximately $0.7 \AA /$ cycle, whereas XRR indicated a slightly higher growth rate of approximately $0.8 \AA /$ cycle. This difference is likely caused by the use of bulk density as well omission of impurities in the EDS thickness calculations. According to XRR, the actual film density was $7.0-7.2 \mathrm{~g} / \mathrm{cm}^{3}$, slightly below the $\mathrm{WS}_{2}$ bulk density of 7.6 $\mathrm{g} / \mathrm{cm}^{3} \cdot{ }^{57}$

EDS revealed that the films were sulfur deficient compared to the target $\mathrm{WS}_{2}$ stoichiometry as well as the $\mathrm{W}_{2} \mathrm{~S}_{3}$ stoichiometry expected from the +3 oxidation state of tungsten in the precursor, although using longer $\mathrm{H}_{2} \mathrm{~S}$ pulses clearly increased the $\mathrm{S} / \mathrm{W}$ atomic ratio. The film thickness increased linearly with increasing number of ALD cycles showing little to no nucleation delay (Fig. 2c).

The deposition temperature had a strong effect on both the growth rate and the film composition. The growth rate increased and the S/W ratio decreased with increasing temperature (Fig. 2d). The lowest deposition temperature of $130{ }^{\circ} \mathrm{C}$ was limited by the 
source temperature of the tungsten precursor $\left(120^{\circ} \mathrm{C}\right)$, whereas the highest deposition temperature was set by decomposition of the tungsten precursor, which was observed to start at $200{ }^{\circ} \mathrm{C}$ as seen by coloration of the glass source tube of the ALD reactor. Interestingly, although the self-limiting ALD behavior was lost at $200{ }^{\circ} \mathrm{C}$, the films deposited at 200 to $300{ }^{\circ} \mathrm{C}$ were relatively uniform, metallic by appearance, and conductive with resistivities of $800-1000 \mu \Omega \mathrm{cm}$. This suggests that $\mathrm{W}_{2}\left(\mathrm{NMe}_{2}\right)_{6}$ may also be a useful low-temperature CVD precursor for tungsten.

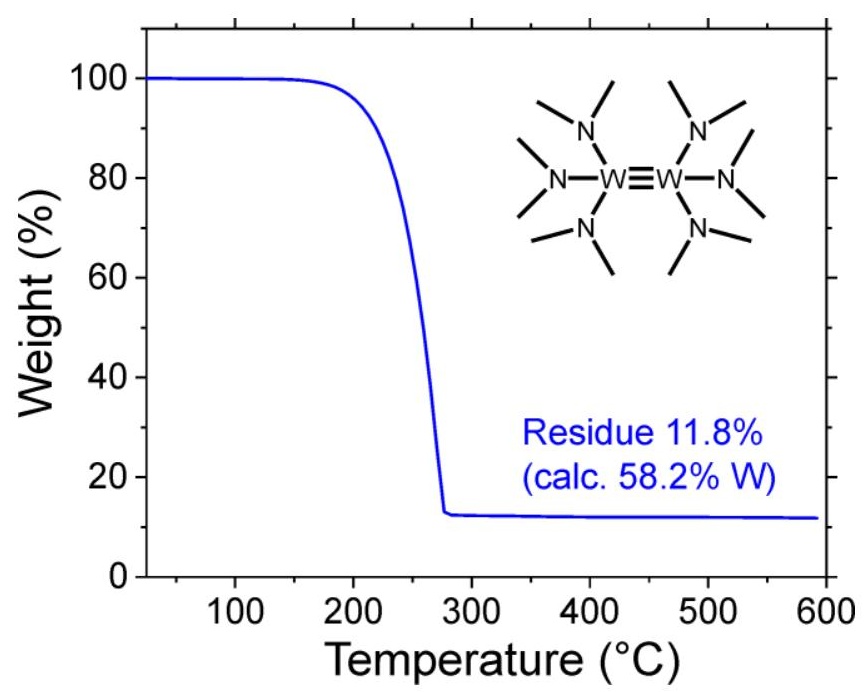

FIG. 1. TGA of $\mathrm{W}_{2}\left(\mathrm{NMe}_{2}\right)_{6}$ (structure shown as an inset) under a $\mathrm{N}_{2}$ atmosphere.

The as-deposited films were practically amorphous, although an unidentified Xray reflection at approximately $9^{\circ} 2 \theta$ was detected in the thickest films deposited using 500 cycles (Fig. S1 in supplementary material) ${ }^{58}$ The peak position corresponds to a d-spacing of approximately $10 \AA$, which is to be compared with the $6.1-6.2 \AA$ spacing of the (002) planes in $2 \mathrm{H}$ or $3 \mathrm{R} \mathrm{WS}$ (Powder Diffraction files PDF 8-0237 and 35-0651, respectively). Such interlayer expansion has been demonstrated for layered TMDCs including $\mathrm{MoS}_{2}$ and $\mathrm{WS}_{2}$ by intercalating various ions, molecules, or graphene sheets, for 
example ${ }^{59}$ Here, the expansion may be due to impurities or disordered $\mathrm{WS}_{\mathrm{x}}$ species inside the van der Waals gap of $\mathrm{WS}_{2}$. Weak peaks attributed to $\mathrm{WS}_{2}$ were also detected by Raman spectroscopy, although the laser seemed to crystallize $\mathrm{WS}_{2}$ during the measurements, despite the use of a very low laser power (Fig. S2 in supplementary material). ${ }^{58}$ Thus, the as-deposited films appear to be poorly ordered structurally, although some hints of $\mathrm{WS}_{2}$ formation were observed.
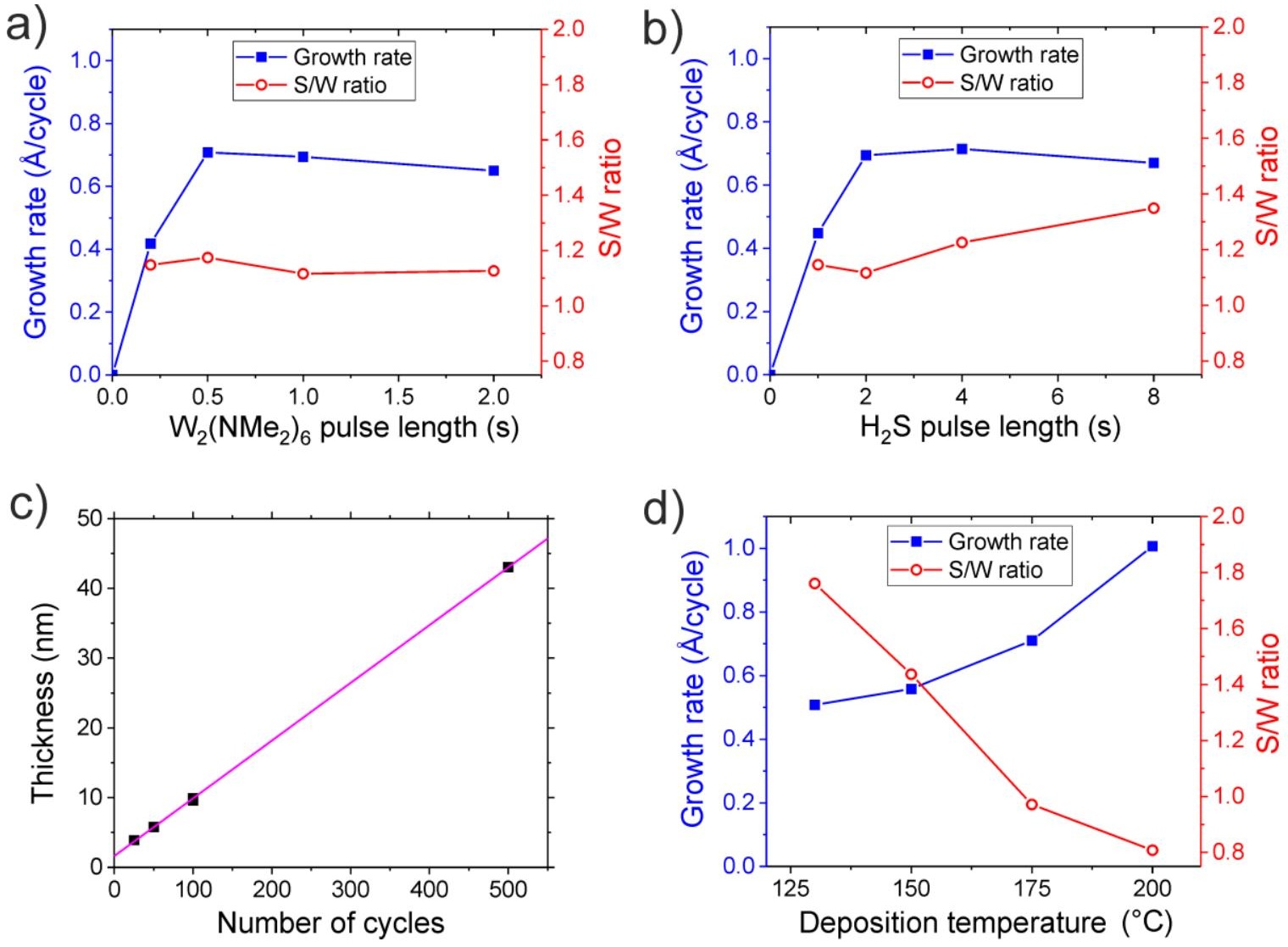

FIG. 2. Growth rate and $\mathrm{S} / \mathrm{W}$ ratio versus a) $\mathrm{W}_{2}\left(\mathrm{NMe}_{2}\right)_{6}$ and b) $\mathrm{H}_{2} \mathrm{~S}$ pulse length. c) Film thickness versus number of ALD cycles. d) Growth rate and S/W ratio versus deposition temperature. Film thicknesses were measured by EDS (a,b,d) or XRR (c). S/W ratio was measured by EDS. Unless otherwise noted, the films were deposited on native oxide covered silicon substrates at $150{ }^{\circ} \mathrm{C}$ using 500 cycles with $1 \mathrm{~s} \mathrm{~W} 2\left(\mathrm{NMe}_{2}\right)_{6}$ and 2 (a) or $4 \mathrm{~s}$ (c,d) $\mathrm{H}_{2} \mathrm{~S}$ pulses separated by $3(\mathrm{a}, \mathrm{b})$ or $2 \mathrm{~s}(\mathrm{c}, \mathrm{d}) \mathrm{N}_{2}$ purges. The line in c) represents a linear fit to the data, whereas the other lines are only to guide the eye. 
The films were very smooth: a 500 cycle film deposited at $150{ }^{\circ} \mathrm{C}$, for example, had a root-mean-square roughness $\left(\mathrm{R}_{\mathrm{q}}\right)$ of only $0.4 \mathrm{~nm}$ (Fig. S3 in supplementary material). ${ }^{58}$ The tungsten sulfide films had a metallic, reflective appearance, which was supported by optical transmittance measurements showing low transmittance from UV to $1100 \mathrm{~nm}$ and no evidence of a band gap (Fig. S4 in supplementary material). ${ }^{58}$ The resistivity of the films ranged from 1 to $10 \mathrm{~m} \Omega \mathrm{cm}$, further corroborating the metallic conductivity of the as-deposited films. The reason for the metallic behavior is not known at present, but is not completely unexpected, as the $1 \mathrm{~T}$ phase of $\mathrm{WS}_{2}$ is metallic. Impurities or sulfur vacancies, for example, could also explain the metallic behavior via heavy doping or the formation of metallic $\mathrm{WN}_{\mathrm{x}}$ or $\mathrm{WC}_{\mathrm{x}}$ species, for example.

Table I. Elemental composition of an as-deposited tungsten sulfide film averaged over the $40 \mathrm{~nm}$ film thickness and on the surface as measured by ToF-ERDA and XPS, respectively. The film was deposited on silicon at $150{ }^{\circ} \mathrm{C}$ using 500 cycles.

\begin{tabular}{ccc}
\hline \hline Element & $\begin{array}{c}\text { Average (at-\%) } \\
\text { ToF-ERDA }\end{array}$ & $\begin{array}{c}\text { Surface (at-\%) } \\
\text { XPS }\end{array}$ \\
\hline $\mathrm{W}$ & $37.9 \pm 0.2$ & 24.7 \\
$\mathrm{~S}$ & $42.0 \pm 0.7$ & 21.8 \\
$\mathrm{~S} / \mathrm{W}$ & $1.11 \pm 0.02$ & 0.88 \\
$\mathrm{C}$ & $7.1 \pm 0.4$ & 29.5 \\
$\mathrm{~N}$ & $3.3 \pm 0.3$ & 1.9 \\
$\mathrm{O}$ & $3.8 \pm 0.3$ & 22.1 \\
$\mathrm{H}$ & $5.8 \pm 1.2$ & Not detectable \\
\hline \hline
\end{tabular}


The average and surface compositions of an approximately $40 \mathrm{~nm}$ film were analyzed by ToF-ERDA and XPS, respectively (Table I). The film was sulfur-deficient and contained carbon, nitrogen, oxygen, and hydrogen impurities. The average S/W ratio of 1.11 is in agreement with the EDS results presented earlier and much lower than that expected for either $\mathrm{W}_{2} \mathrm{~S}_{3}$ (1.5) or $\mathrm{WS}_{2}$ (2.0). The high surface carbon content detected by XPS is due to atmospheric contamination, as the films were not sputtered prior to the analysis. Oxygen appears to originate from surface oxidation of the films in air, whereas the other impurities detected by ToF-ERDA $(\mathrm{C}, \mathrm{N}, \mathrm{H})$ are likely due to incomplete removal of the ligands of the $\mathrm{W}_{2}\left(\mathrm{NMe}_{2}\right)_{6}$ precursor. The impurity contents were similar to those of the ALD tungsten oxide and nitride films deposited using the same tungsten precursor, except for the lower hydrogen content of our $\mathrm{WS}_{\mathrm{x}}$ films. ${ }^{60,61}$

\section{B. Post-deposition annealing}

In order to crystallize the films, we annealed them in the ALD reactor in a flowing $\mathrm{H}_{2} \mathrm{~S} / \mathrm{N}_{2}(14 / 400 \mathrm{sccm}, \sim 5 \mathrm{mbar}$ total pressure) atmosphere. This approach has proven to be effective in producing crystalline and smooth $\mathrm{SnS}_{2}$ films while retaining a low thermal budget and requiring no additional annealing equipment. ${ }^{62}$ Initially, temperatures from 300 to $500{ }^{\circ} \mathrm{C}$ were tested for approximately $9 \mathrm{~nm}$ thick tungsten sulfide films deposited using 100 cycles.

While annealing at $300{ }^{\circ} \mathrm{C}$ resulted in little improvement in the crystallinity of the films, annealing at 400 and especially $500{ }^{\circ} \mathrm{C}$ led to a clear increase in the intensities of the Raman (Fig. 3a) and XRD (Fig. 3b) peaks attributed to the $2 \mathrm{H}$ or $3 \mathrm{R}$ phase of $\mathrm{WS}_{2}$. Both the $2 \mathrm{H}$ and $3 \mathrm{R}$ phases have similar structures differing only by the stacking of the $\mathrm{WS}_{2}$ layers. ${ }^{3}$ Thus, we could not distinguish between them or other stacking 
arrangements. The broadness of both the Raman and the XRD peaks even after annealing suggests that the films were nanocrystalline. The surface composition also improved with the best results seen after the annealing at $400{ }^{\circ} \mathrm{C}$, resulting in a $\mathrm{S} / \mathrm{W}$ ratio of 1.82 (Table II). The slight sulfur deficiency may be due to surface oxidation, which is commonly observed for synthetic $\mathrm{WS}_{2}$ and other TMDCs. ${ }^{63-65}$ Increasing the annealing temperature to $500{ }^{\circ} \mathrm{C}$ resulted in a lower $\mathrm{S} / \mathrm{W}$ ratio and a higher oxygen content compared to the films annealed at $400{ }^{\circ} \mathrm{C}$, perhaps due to the rough morphology discussed below. The nitrogen content decreased to one third of the original (as-deposited) value after annealing at $400{ }^{\circ} \mathrm{C}$, which suggests removal of impurities from the films during annealing. Unfortunately, we were unable to reliably determine the carbon and hydrogen contents of the films after annealing, as the annealed films were too thin for ToF-ERDA and the ambient hydrocarbon contamination distorted the carbon levels detected by XPS. 


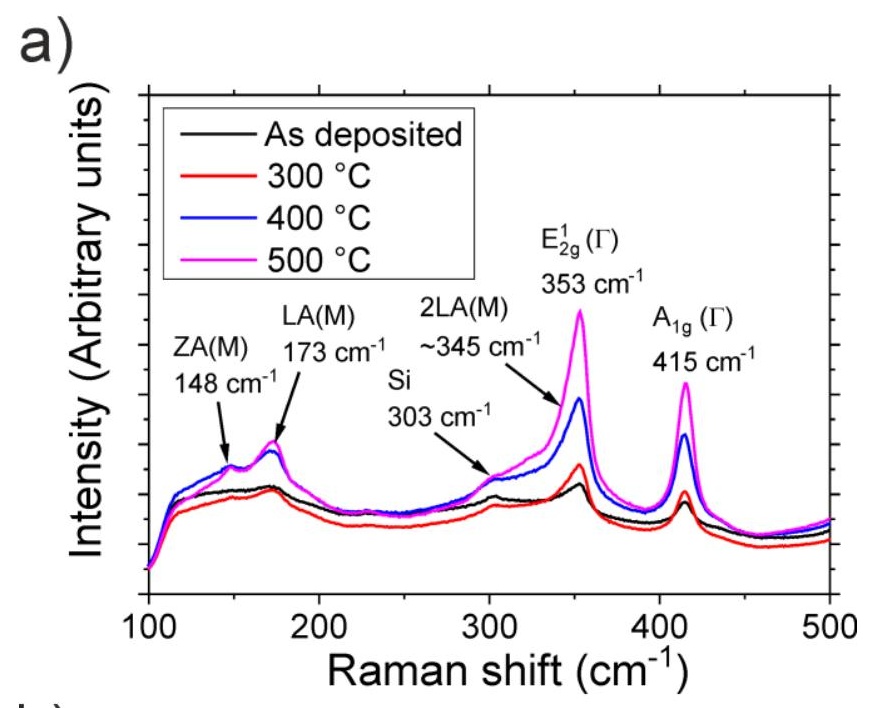

b)

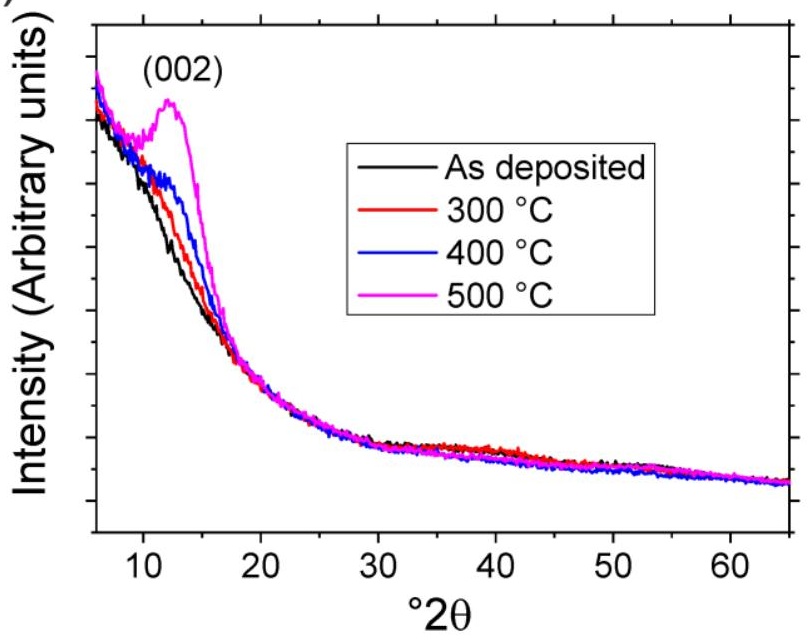

FIG. 3. a) Raman spectra and b) grazing incidence $X$-ray diffractograms of tungsten sulfide films as-deposited and after annealing at different temperatures. The films were deposited on silicon at $150{ }^{\circ} \mathrm{C}$ using 100 cycles and the annealing was done in $\mathrm{H}_{2} \mathrm{~S} / \mathrm{N}_{2}$ atmosphere for $1 \mathrm{~h}$. The Raman and XRD peaks of $\mathrm{WS}_{2}$ were indexed according to Ref.66 and Powder Diffraction File (PDF) 8-0237, respectively.

Table II. Elemental surface composition of tungsten sulfide films as-deposited and after annealing as analyzed by XPS. The films were deposited on silicon at $150{ }^{\circ} \mathrm{C}$ using 100 cycles and the annealing was done in $\mathrm{H}_{2} \mathrm{~S} / \mathrm{N}_{2}$ atmosphere for $1 \mathrm{~h}$.

\begin{tabular}{lllll}
\hline \hline Element & As-deposited & $300{ }^{\circ} \mathrm{C}$ & $400{ }^{\circ} \mathrm{C}$ & $500{ }^{\circ} \mathrm{C}$ \\
\hline
\end{tabular}




\begin{tabular}{ccccc}
\hline \hline & (at-\%) & (at-\%) & (at-\%) & (at-\%) \\
\hline $\mathrm{W}$ & 22.6 & 21.4 & 16.2 & 17.1 \\
$\mathrm{~S}$ & 19.6 & 26.0 & 29.5 & 26.7 \\
$\mathrm{~S} / \mathrm{W}$ & 0.87 & 1.22 & 1.82 & 1.56 \\
$\mathrm{C}$ & 30.2 & 33.8 & 37.9 & 27.9 \\
$\mathrm{~N}$ & 3.1 & 1.8 & 1.0 & 0.8 \\
$\mathrm{O}$ & 24.6 & 16.9 & 14.2 & 27.5 \\
\hline \hline
\end{tabular}

Core-level photoelectron spectra of $\mathrm{W} 4 \mathrm{f}$ and $\mathrm{S} 2 \mathrm{p}$ regions corroborated $400{ }^{\circ} \mathrm{C}$ as the optimal annealing temperature. Three doublets were fitted to the $\mathrm{W} 4 \mathrm{f}$ spectra representing $\mathrm{WS}_{2}$ at binding energies of 32.4 and $34.6 \mathrm{eV}$ for the $\mathrm{W} 4 \mathrm{f}_{7 / 2}$ and $\mathrm{W} 4 \mathrm{f}_{5 / 2}$ levels, respectively, $\mathrm{WS}_{\mathrm{x}} \mathrm{O}_{\mathrm{y}}$ or $\mathrm{WO}_{2}$ at binding energies of 33.3 and $35.5 \mathrm{eV}$, and $\mathrm{WO}_{3}$ at 35.8 and $38.0 \mathrm{eV}$ (Fig. 4a). ${ }^{67-69}$ The binding energies of the $\mathrm{WS}_{2}$ doublet are in agreement with the semiconducting $2 \mathrm{H}$ or $3 \mathrm{R}$ phases of $\mathrm{WS}_{2}$, whereas the metallic $1 \mathrm{~T}$ phase would result in lower binding energies. ${ }^{3,67-69}$ The $\mathrm{WO}_{3}$ content relative to the total $\mathrm{W}$ content, which likely originates from the oxidation of the films in air, was the lowest at 17\% in the sample annealed at $400{ }^{\circ} \mathrm{C}$, compared with $51 \%$ in the as-deposited film and 32 and $23 \%$ in the films annealed at 300 and $500{ }^{\circ} \mathrm{C}$, respectively. Similarly, the relative $\mathrm{WS}_{2}$ content reached its maximum $(74 \%)$ after annealing at $400{ }^{\circ} \mathrm{C}$.

The $\mathrm{S} 2 \mathrm{p}$ region expectedly contained a doublet corresponding to $\mathrm{S}^{2-}$ in $\mathrm{WS}_{2}$ with binding energies of $162.1\left(\mathrm{~S} 2 \mathrm{p}_{3 / 2}\right)$ and $163.3 \mathrm{eV}\left(\mathrm{S}_{2} \mathrm{p}_{1 / 2}\right)$ as shown in Figure $4 \mathrm{~b} \cdot{ }^{67-70}$ The broadening of the $\mathrm{S} 2 \mathrm{p}$ peak was attributed to the presence of substoichiometric $\mathrm{WS}_{\mathrm{z}}(\mathrm{z}<$ 2) at binding energies of 161.2 and $162.4 \mathrm{eV}$ and sulfur in oxysulfide or organic environment at 163.3 and $164.4 \mathrm{eV}$ for the $\mathrm{S} 2 \mathrm{p}_{3 / 2}$ and $\mathrm{S} 2 \mathrm{p}_{1 / 2}$ levels, respectively. ${ }^{68-70}$ 
The relative content of the $\mathrm{WS}_{2}$-bound sulfur to the total sulfur content increased with increasing annealing temperature from $47 \%$ in the as-deposited film to 68,71 , and $78 \%$ in the films annealed at 300,400 , and $500{ }^{\circ} \mathrm{C}$, respectively. The improvement was also qualitatively seen in the improved resolution of the $S 2 p$ doublet with increasing annealing temperature.
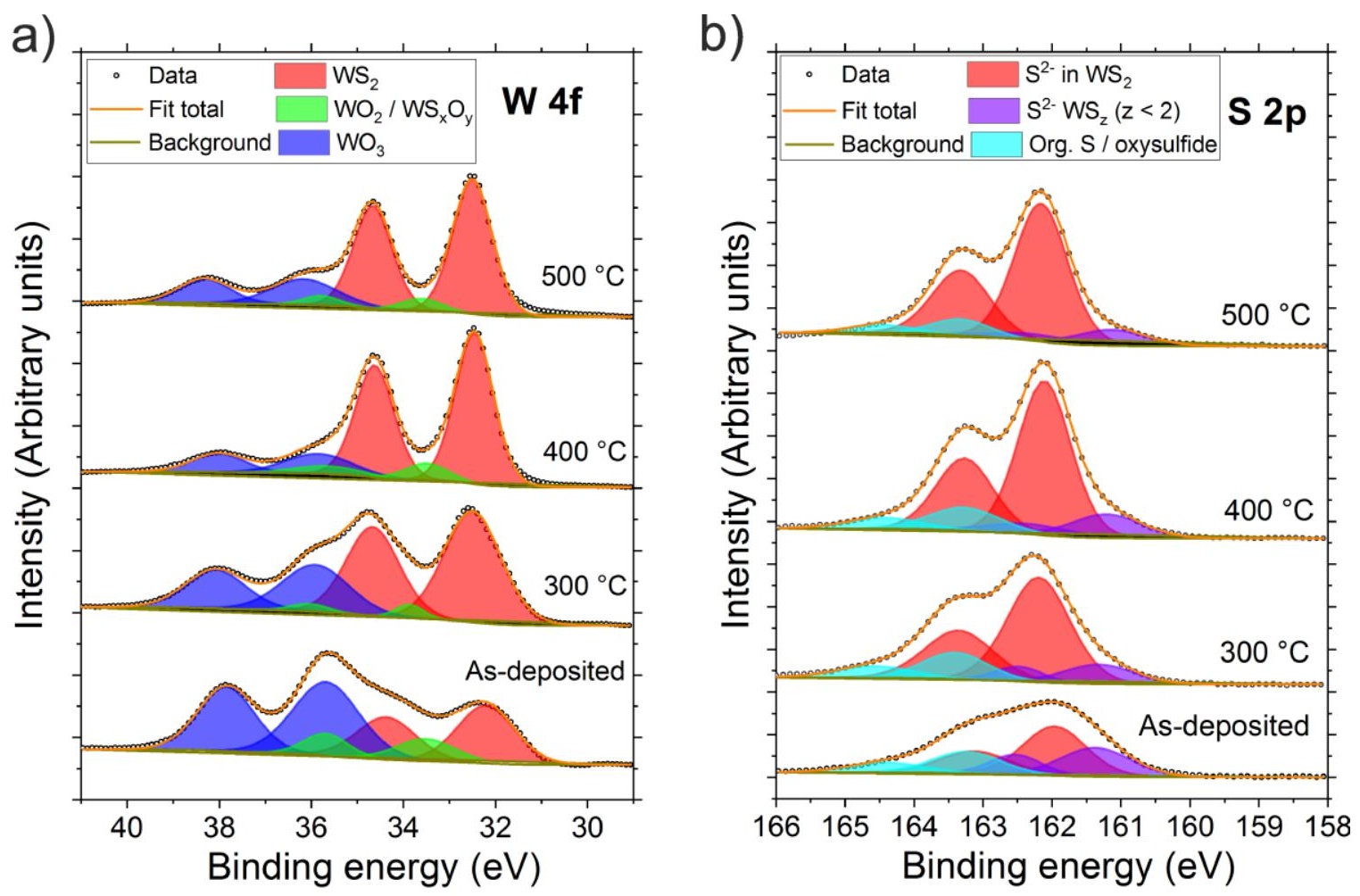

FIG. 4. X-ray photoelectron spectra of a) W $4 \mathrm{f}$ and b) S 2p regions. The films were deposited on silicon at $150{ }^{\circ} \mathrm{C}$ using 100 cycles. The annealing was done in $\mathrm{H}_{2} \mathrm{~S} / \mathrm{N}_{2}$ atmosphere for $1 \mathrm{~h}$.

The films remained smooth when annealed at $400{ }^{\circ} \mathrm{C}$ or below, whereas annealing at $500{ }^{\circ} \mathrm{C}$ led to a very rough morphology with up to $50 \mathrm{~nm}$ high particles or crystallites present on the surface of the nominally $9 \mathrm{~nm}$ thick film (Fig. 5).

Further evidence for the formation of $\mathrm{WS}_{2}$ at $400{ }^{\circ} \mathrm{C}$ and above was obtained from optical transmission measurements, which showed a clear change compared to the 
as-deposited films (Fig. S5 in supplementary material). ${ }^{58}$ Using a Tauc plot, an indirect band gap of approximately $1.2 \mathrm{eV}$, close to the $\mathrm{WS}_{2}$ bulk band gap of $1.3-1.4 \mathrm{eV},{ }^{20}$ was estimated for the films annealed at 400 and $500{ }^{\circ} \mathrm{C}$. Notably, this is in contrast to the apparently metallic behavior of the as-deposited films.
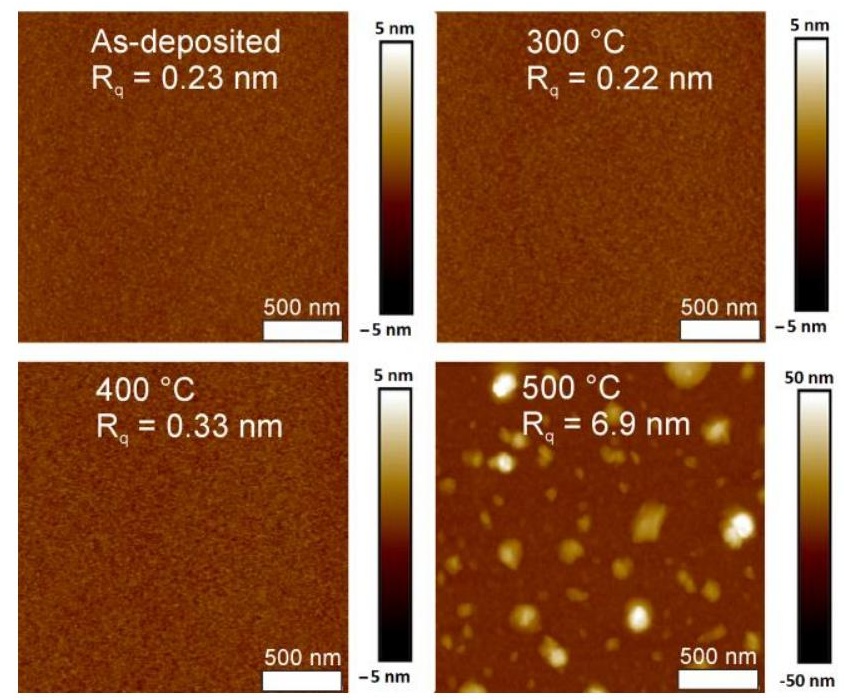

FIG. 5. AFM images and roughness $\left(\mathrm{R}_{\mathrm{q}}\right)$ values of tungsten sulfide films as-deposited and after annealing at different temperatures. Note the different height scale for the sample annealed at $500{ }^{\circ} \mathrm{C}$. The films were deposited on silicon at $150{ }^{\circ} \mathrm{C}$ using 100 cycles and the annealing was done in $\mathrm{H}_{2} \mathrm{~S} / \mathrm{N}_{2}$ atmosphere for $1 \mathrm{~h}$.

\section{Scaling down the thickness: towards few-layer $W_{2}$}

We proceeded to produce ultrathin $(<10 \mathrm{~nm}) \mathrm{WS}_{2}$ films by annealing the asdeposited films at $400{ }^{\circ} \mathrm{C}$, the temperature which offered the best combination of crystallinity, stoichiometry, and smooth morphology. Linear thickness control was demonstrated to hold also at thicknesses below $10 \mathrm{~nm}$ (Fig. 6a). Although we were unable to determine the thickness of the thinnest film deposited using 10 cycles, linear fit suggests its thickness to be close to $1.2 \mathrm{~nm}$, which corresponds to two monolayers of $\mathrm{WS}_{2}$ (monolayer thickness $0.62 \mathrm{~nm}$ ). Furthermore, all of the the films deposited using 10 
to 100 cycles were very smooth and continuous even after the $400{ }^{\circ} \mathrm{C}$ post-deposition annealing treatment (Fig. 6b).

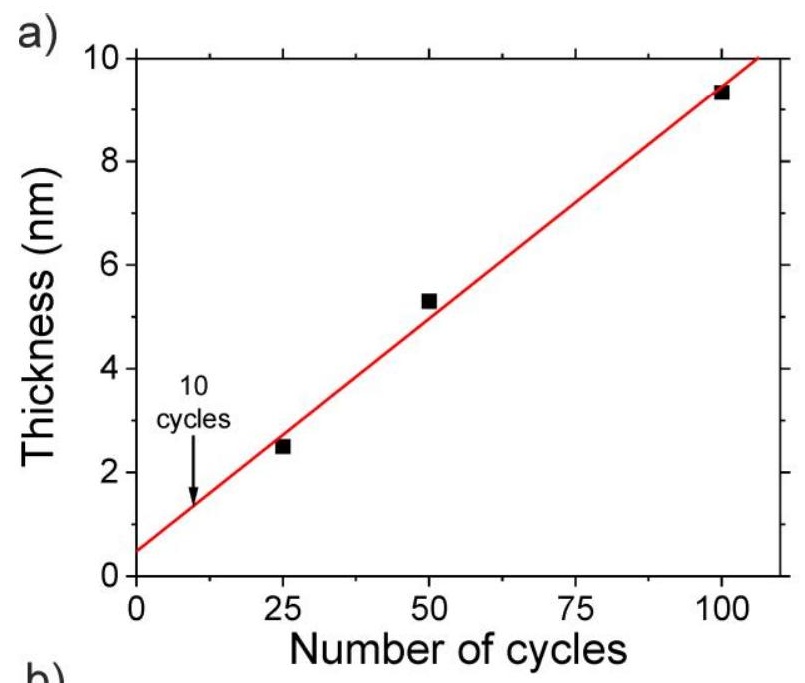

b)
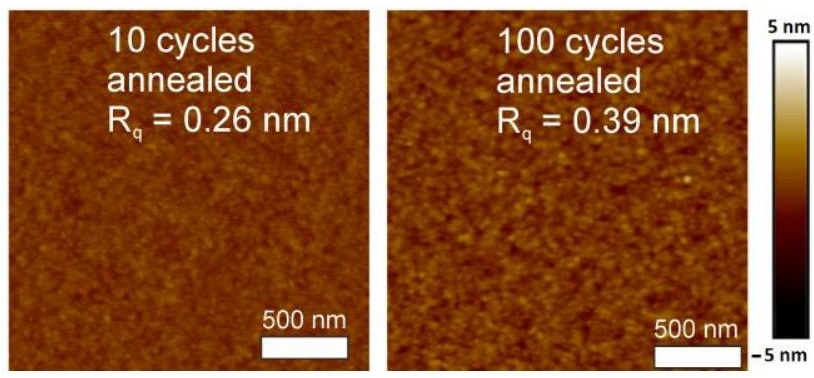

FIG. 6. a) Thickness of annealed tungsten sulfide films, where the red line represents linear fit to the data and arrow shows the estimated thickness of the 10 cycle film assuming linear growth. b) AFM images of annealed tungsten sulfide films. The films were deposited at $150{ }^{\circ} \mathrm{C}$ and annealed at $400{ }^{\circ} \mathrm{C}$ for $1 \mathrm{~h}$.

Raman spectroscopy confirmed that the 10 to 100 cycle films crystallized as $\mathrm{WS}_{2}$ when annealed at $400{ }^{\circ} \mathrm{C}$ (Fig. 7a). For simplicity, the Raman modes discussed here are denoted according to the $\mathrm{D}_{6 \mathrm{~h}}$ symmetry of bulk $2 \mathrm{H}-\mathrm{WS} \mathrm{S}_{2}$. As reported for $2 \mathrm{H}-\mathrm{WS}_{2}$, in addition to the $\mathrm{E}_{2 \mathrm{~g}}^{1}$ and $\mathrm{A}_{1 \mathrm{~g}}$ modes at the center of the Brillouin zone, longitudinal acoustic mode at the M point of the Brillouin zone LA(M) and its overtone 2LA(M) were observed due to resonance effects with the $532 \mathrm{~nm}$ laser. ${ }^{66}$ To properly fit the low- 
frequency side of the $\mathrm{E}^{1}{ }_{2 \mathrm{~g}} / 2 \mathrm{LA}(\mathrm{M})$ peak, a broad mode near $330 \mathrm{~cm}^{-1}$ was also included. This mode was denoted as the $\mathrm{E}^{1}{ }_{2 \mathrm{~g}}(\mathrm{M})$ mode according to Su et al., ${ }^{71}$ although Liu et al. ${ }^{72}$ suggested this to be the $\mathrm{B}^{1}{ }_{2 \mathrm{~g}}(\mathrm{~K})$ and Zhang et al. ${ }^{73}$ the $\mathrm{E}^{\prime}{ }^{\prime}(\mathrm{M})^{\mathrm{TO}}$ mode (Fig. $7 \mathrm{~b}$ ).

a)

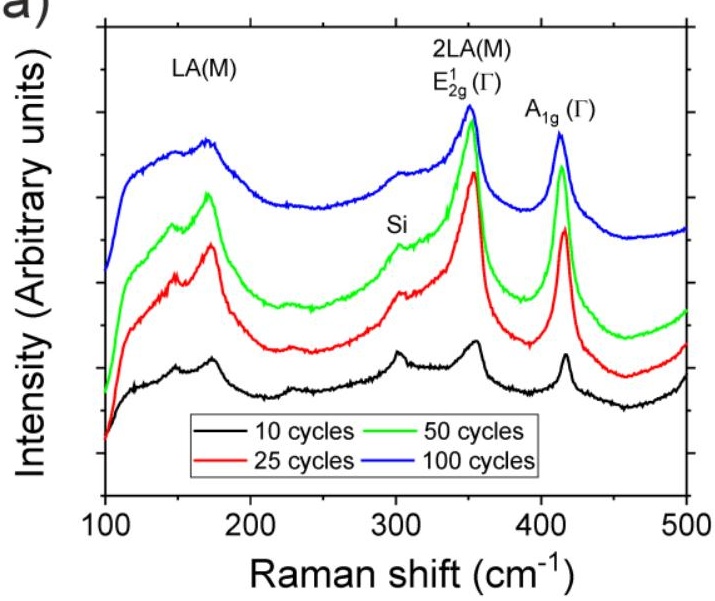

C) Thickness in monolayers (all symbols)

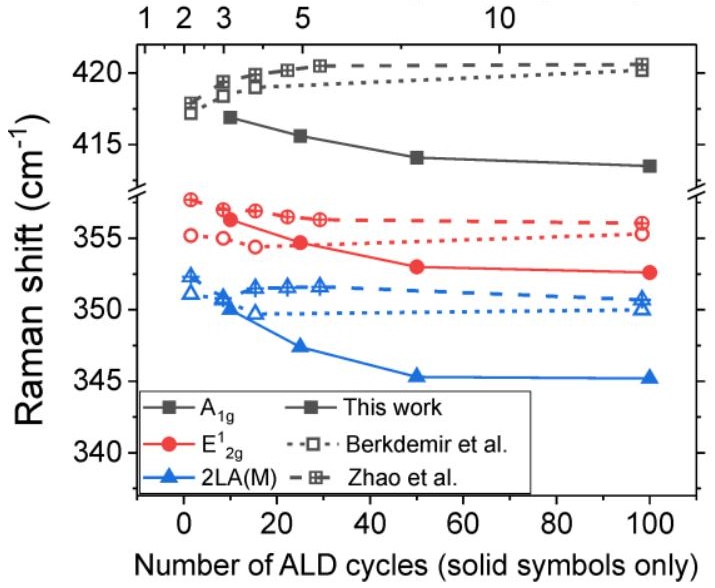

b)

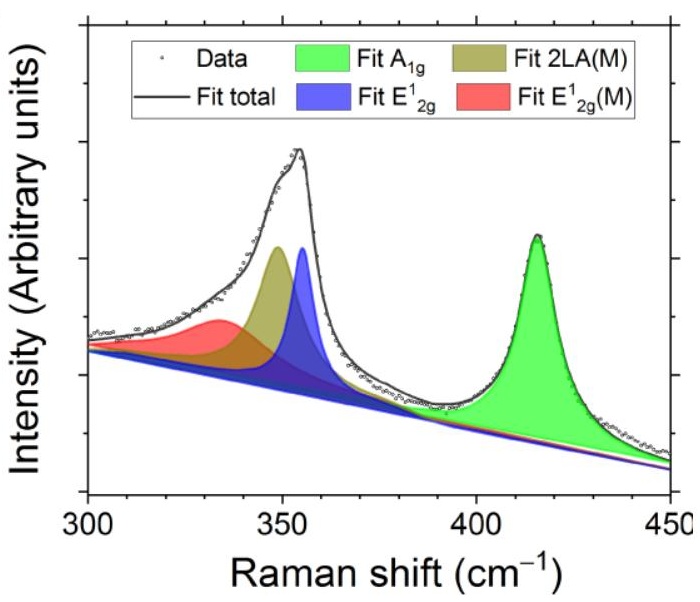

d) Thickness in monolayers (all symbols)

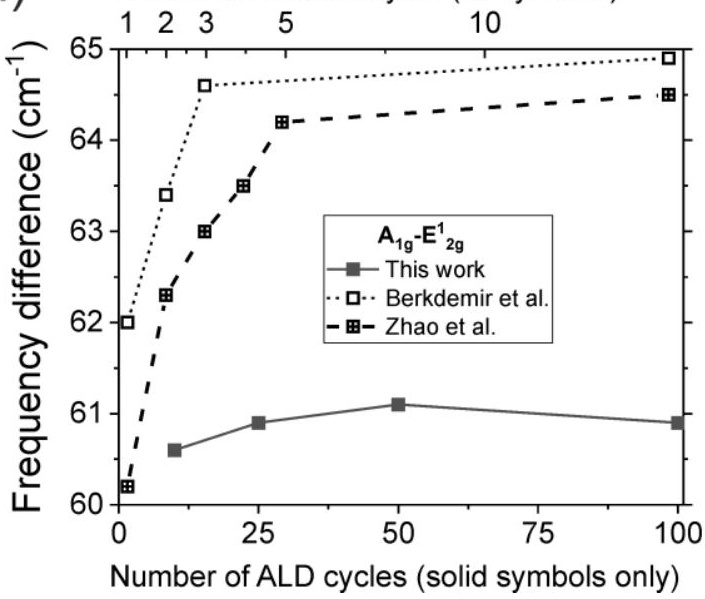

FIG. 7. a) Raman spectra of $\mathrm{WS}_{2}$ films of different thicknesses after annealing at $400{ }^{\circ} \mathrm{C}$. b) Raman spectrum of a 25 cycle $\mathrm{WS}_{2}$ film annealed at $400{ }^{\circ} \mathrm{C}$ showing the modes fitted between 300 and $450 \mathrm{~cm}^{-1}$. c) Fitted positions of the $A_{1 g}, E^{1}{ }_{2 g}$, and $2 \mathrm{LA}(\mathrm{M})$ modes and $\mathrm{d}$ ) frequency difference $\mathrm{A}_{1 \mathrm{~g}}-\mathrm{E}^{1}{ }_{2 \mathrm{~g}}$ of $\mathrm{WS}_{2}$ films of different thicknesses. Open and crossed symbols in c) and d) represent literature values from Berkdemir et al. (CVD-grown flakes $)^{66}$ and Zhao et al. (exfoliated flakes) ${ }^{74}$ respectively. 
Frequencies of the Raman modes are commonly used to determine the thickness of $\mathrm{WS}_{2}$ and other TMDCs, especially at thicknesses below 5 monolayers. ${ }^{66,74,75}$ Typically, a blueshift of the in-plane $\mathrm{E}^{1}{ }_{2 \mathrm{~g}}$ (increase of Raman shift/frequency) and a redshift of the out-of-plane $A_{1 g}$ mode (decrease of Raman frequency) are observed with decreasing thickness, which results in decreased separation between these two modes. ${ }^{66,74,75}$ Here, however, the $A_{1 g}, E_{2 g}^{1}$, and $2 \mathrm{LA}(\mathrm{M})$ modes were all observed to blueshift when the number of ALD cycles (thickness) was decreased (Fig. 7c), whereas the $A_{1 g}-E^{1}{ }_{2 g}$ frequency difference changed by no more than $0.5 \mathrm{~cm}^{-1}$ (Fig. 7d). Thus, the mode frequencies observed for exfoliated $\mathrm{WS}_{2}$ flakes, as studied by Zhang et al., ${ }^{73}$ or CVDgrown triangular flakes, as studied by Berkdemir et al., ${ }^{66}$ cannot be used to determine the thicknesses of our films.

Two possible explanations for the different frequency-thickness trends observed here are the strain and doping of the films, both of which are known to affect the Raman frequencies of TMDCs. ${ }^{15,16,18,71,75}$ Strain is often formed in TMDCs as a result of different thermal expansion of the film and the substrate as well as film-substrate bonding. Here, the changes in film composition and structure during annealing are also likely to affect the strain. The positions of the in-plane $\mathrm{E}^{1}{ }_{2 \mathrm{~g}}$ mode and the $2 \mathrm{LA}(\mathrm{M})$ mode are sensitive to in-plane strain, showing redshifts of $2-3 \mathrm{~cm}^{-1}$ per one percent of tensile strain, ${ }^{15}$ whereas the out-of-plane $\mathrm{A}_{1 \mathrm{~g}}$ mode is expected to be sensitive to out-of-plane strain. Studies of $\mathrm{WS}_{2}$ monolayers on different substrates have also shown changes in frequencies of up to $5 \mathrm{~cm}^{-1}$ for both the $\mathrm{A}_{1 \mathrm{~g}}$ and the $\mathrm{E}^{1}{ }_{2 \mathrm{~g}}$ modes depending on the substrate, at least partly due to strain..$^{71,76}$ The observed redshifts especially in our thicker films would imply a tensile strain. Regarding doping, a redshift of the $\mathrm{A}_{1 \mathrm{~g}}$, and to a 
smaller degree of the $\mathrm{E}^{1}{ }_{2 \mathrm{~g}}$ mode, has been observed with increasing carrier

concentration. ${ }^{18,77}$ We speculate that strain may be the most likely explanation for the observed Raman shifts in our films due to the relatively large magnitude of the observed redshifts, the increase of the redshifts with increasing thickness as well as the disordered film structure, which will be discussed later.

The Raman peaks of our $\mathrm{WS}_{2}$ films were relatively wide: the full-width at halfmaximum (FWHM) values of the $A_{1 g}$ and $E^{1}{ }_{2 g}$ peaks increased from about 8 and 6 to 9 and $14 \mathrm{~cm}^{-1}$, respectively, when the number of ALD cycles was increased from 10 to 100 (Fig. S6 in supplementary material). ${ }^{58} \mathrm{WS}_{2}$ flakes exfoliated from bulk crystals have been reported to have FWHM of $2-4 \mathrm{~cm}^{-1}$ for these modes, ${ }^{44,74}$ which suggests that our films exhibit considerable disorder compared to pristine $\mathrm{WS}_{2}$. Additionally, the disorder seems to increase with increasing number of ALD cycles, consistent with the mode frequencies shifting further away from their expected values. For comparison, a 3 ML thick PEALD $\mathrm{WS}_{2}$ film grown at $300{ }^{\circ} \mathrm{C}$ had FWHM of 9 and $5 \mathrm{~cm}^{-1}$ for the $\mathrm{A}_{1 \mathrm{~g}}$ and $\mathrm{E}^{1}{ }_{2 \mathrm{~g}}$ modes, respectively. ${ }^{44}$ On the other hand, $4 \mathrm{ML} \mathrm{WS}$ films produced by sulfurizing ALD-WO films yielded $\mathrm{A}_{1 \mathrm{~g}}$ and $\mathrm{E}_{2 \mathrm{~g}}^{1} \mathrm{FWHM}$ as large as 16 and $10 \mathrm{~cm}^{-1}$ when the sulfurization was done at $600{ }^{\circ} \mathrm{C}$, and still 12 and $9 \mathrm{~cm}^{-1}$ for the films sulfurized at $900{ }^{\circ} \mathrm{C}{ }^{78}$

The microstructure of an annealed 50 cycle $\mathrm{WS}_{2}$ film was further evaluated by HAADF-STEM. The film was observed to be smooth and continuous, in accordance with the AFM results (Fig. 8a). The film thickness of approximately $5.5 \mathrm{~nm}$, corresponding to about 9 monolayers of $\mathrm{WS}_{2}$, was in excellent agreement with XRR $(5.3 \mathrm{~nm})$.

Furthermore, the film had a sharp interface with the native oxide layer underneath and no obvious oxidized layer was observed on top of the film. The $\mathrm{WS}_{2}$ film consisted of small, 
about 3-10 nm wide crystallites, which exhibited the expected layered structure of $\mathrm{WS}_{2}$ (Fig. 8). However, the basal planes were found to be randomly oriented with respect to the substrate and even strongly bent in several locations. Additionally, many of the crystallites appeared to be only a few monolayers thick (Fig. 8c). This disordered structure is in accordance with the observed wide XRD and Raman peaks and may explain the different Raman shifts compared to exfoliated and CVD-grown flakes. According to the HAADF-STEM images, the distance between the (002) basal planes varied between approximately 6 and $7 \AA$ with an average of $6.5 \AA$, which is slightly more than the expected values of $6.18 \AA$ or $6.13 \AA$ for the $2 \mathrm{H}$ and $3 \mathrm{R}$ phases (PDF 8-0237 and 35-0651, respectively). Another set of planes was observed with an interplane spacing of $2.8 \AA$, which is in good agreement with the (100) and (101) planes of $\mathrm{WS}_{2}$ with expected spacings of approximately $2.7 \AA$. Unfortunately, we could not definitively identify whether the layers were stacked in $2 \mathrm{H}, 3 \mathrm{R}$, or some other polytype.

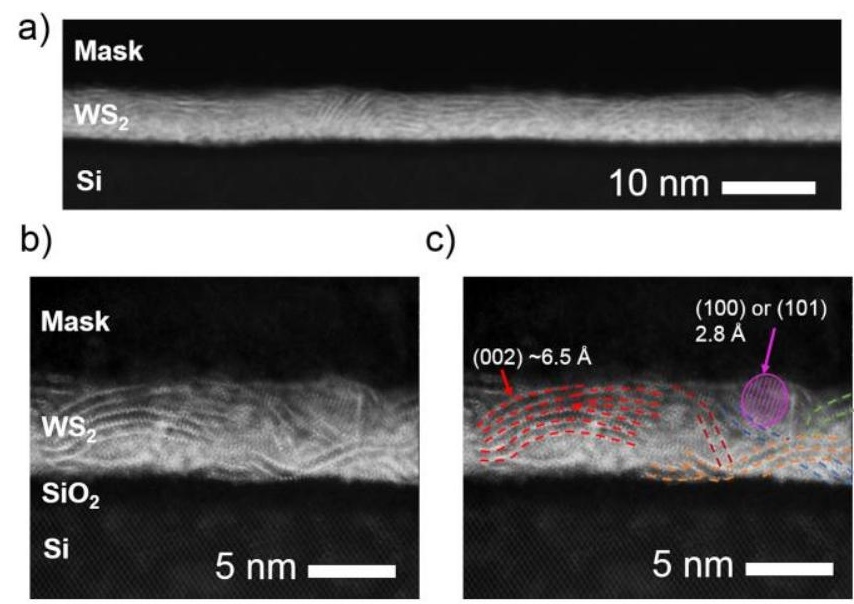

FIG. 8. a) Low and b) high magnification HAADF-STEM images of a 50 cycle $\mathrm{WS}_{2}$ film annealed at $400{ }^{\circ} \mathrm{C}$. c) (002) (dashed) and (100) or (101) planes (solid) highlighted in the high magnification image along with the estimated interplane distances. 


\section{Comparison to other processes}

Finally, we briefly compare our process and the deposited films to the existing $\mathrm{WS}_{2}$ ALD processes (Table III). Our deposition temperature of $150{ }^{\circ} \mathrm{C}$ is the lowest among the reported processes, and even our annealing temperature of $400{ }^{\circ} \mathrm{C}$ is similar to the deposition temperature of many of the $\mathrm{WS}_{2}$ ALD processes. Therefore, it is not surprising that the deposited films were amorphous similar to the $\mathrm{W}(\mathrm{CO})_{6}+\mathrm{H}_{2} \mathrm{~S}$ process operated at $165-205^{\circ} \mathrm{C}$. Unfortunately, the comparison to our well-behaving ALD process is hindered by the fact that the saturative nature of the surface reactions, an important characteristic of ALD, has not been evaluated for many of the reported processes. Furthermore, prior to our work, only a few of the reported processes have been used to deposit ultrathin 2D films of $\mathrm{WS}_{2}$. The composition and structure of our annealed films as judged by the $\mathrm{S} / \mathrm{W}$ ratio as well as the grain size are similar to most of the processes. So far, the best crystallinity seems to have been obtained using plasmaenhanced ALD, but the use of plasma adds process complexity and may limit the conformality of the films. Detailed studies on issues critical to the growth of 2D films, including nucleation, grain growth, film closure, and effect of substrate have been performed with the $\mathrm{WF}_{6}+\mathrm{H}_{2}$ plasma $+\mathrm{H}_{2} \mathrm{~S}$ process ${ }^{43-46}$ whereas corresponding understanding is lacking for the other reported processes. Thus, further studies on our process as well as the other processes are needed in the future to assess their full potential in the growth of $2 \mathrm{D} \mathrm{WS}$. 
Table III. Reported $\mathrm{WS}_{2}$ ALD processes and characteristics of deposited films.

\begin{tabular}{|c|c|c|c|c|c|c|c|}
\hline Precursors & $\begin{array}{c}\text { Deposition } \\
\text { (annealing) } \\
\text { temperature } \\
\left({ }^{\circ}\right)\end{array}$ & $\begin{array}{c}\text { Growth } \\
\text { rate } \\
(\AA / \text { cycle })\end{array}$ & $\begin{array}{l}\text { Satura } \\
\text { tion }\end{array}$ & $\begin{array}{c}\text { Thickness } \\
\text { (nm) }\end{array}$ & $\begin{array}{l}\text { Grain } \\
\text { size } \\
(\mathrm{nm})\end{array}$ & $\begin{array}{l}\mathrm{S} / \mathrm{W} \\
\text { ratio }\end{array}$ & Ref. \\
\hline $\begin{array}{c}\mathrm{W}_{2}\left(\mathrm{NMe}_{2}\right)_{6} \\
+\mathrm{H}_{2} \mathrm{~S}\end{array}$ & $150(400)$ & $0.8-0.9$ & yes & $\sim 2-10$ & $\sim 3-10$ & 1.8 & $\begin{array}{l}\text { This } \\
\text { work }\end{array}$ \\
\hline $\mathrm{WF}_{6}+\mathrm{H}_{2} \mathrm{~S}^{\mathrm{b}}$ & $300-350$ & $\sim 1$ & $-^{a}$ & $10-300$ & $5-100$ & - & 47,49 \\
\hline \multirow[t]{2}{*}{$\begin{array}{c}\mathrm{WF}_{6}+\mathrm{H}_{2} \\
\text { plasma }+ \\
\mathrm{H}_{2} \mathrm{~S}\end{array}$} & $250-450$ & $\sim 0.2$ & yes & $\sim 1-3$ & $\sim 10$ & $\begin{array}{c}1.8 \pm 0 \\
1\end{array}$ & $43-45$ \\
\hline & 450 & $\sim 0.2$ & yes & $<1-5$ & $\begin{array}{l}\text { up to } \\
200\end{array}$ & $\begin{array}{c}1.8 \pm 0 \\
1\end{array}$ & 46 \\
\hline $\begin{array}{c}\mathrm{WCl}_{5}+ \\
\mathrm{H}_{2} \mathrm{~S}\end{array}$ & 390 & 1.25 & $-^{\mathrm{a}}$ & $<5$ & cryst. $^{\mathrm{c}}$ & - & 53 \\
\hline \multirow[t]{2}{*}{$\begin{array}{c}\mathrm{W}(\mathrm{CO})_{6}+ \\
\mathrm{H}_{2} \mathrm{~S}\end{array}$} & $165-205$ & $\sim 0.2$ & yes & $20-40$ & amorph & 2.05 & 50 \\
\hline & 400 & 3.6 & $--^{a}$ & 175 & $\sim 5$ & - & 51 \\
\hline $\begin{array}{c}\mathrm{W}(\mathrm{CO})_{6}+ \\
\mathrm{H}_{2} \mathrm{~S} \text { plasma }\end{array}$ & 350 & $\sim 1$ & yes & $3-20$ & $3-7$ & 1.94 & 52 \\
\hline
\end{tabular}

${ }^{a}$ Not evaluated, ${ }^{b}$ no growth unless $\mathrm{ZnS}$ substrate or $\mathrm{ZnEt}_{2}$ pulses were applied, ${ }^{\mathrm{c}}$ film crystalline, but grain size not indicated. 


\section{IV.SUMMARY AND CONCLUSIONS}

In this work, we demonstrated atomic layer deposition of tungsten sulfide thin films using a dimeric amide $\mathrm{W}_{2}\left(\mathrm{NMe}_{2}\right)_{6}$ and $\mathrm{H}_{2} \mathrm{~S}$ as precursors. The process exhibited good ALD characteristics at a low temperature of $150{ }^{\circ} \mathrm{C}$. The as-deposited films were smooth and amorphous with a S/W atomic ratio close to 1 and apparently metallic behavior. A postdeposition annealing treatment in $\mathrm{H}_{2} \mathrm{~S} / \mathrm{N}_{2}$ atmosphere at $400{ }^{\circ} \mathrm{C}$, a low temperature compared to most previous studies on $\mathrm{WS}_{2}$, resulted in near-stoichiometric, crystalline, and semiconducting $\mathrm{WS}_{2}$ films. We demonstrated that crystalline and smooth $\mathrm{WS}_{2}$ films can be deposited in a wide thickness range from a few monolayers to ten nm using the present process. Detailed inspection of film microstructure using Raman spectroscopy, XRD, and HAADF-STEM showed that the films were composed of randomly oriented, nanocrystalline $\mathrm{WS}_{2}$ grains exhibiting notable disorder. Supported by the excellent scalability and thickness control of ALD as well as the relatively low thermal budget, our process might be especially interesting for large-scale energy applications including lithium-ion batteries and hydrogen evolution reaction, where a defect-rich structure is often beneficial.

\section{ACKNOWLEDGMENTS}

The research was supported by ASM Microchemistry and the Finnish Centre of Excellence in Atomic Layer Deposition funded by Academy of Finland. EAG Laboratories are acknowledged for TEM sample preparation and imaging. The authors acknowledge the provision of XRD facilities by Aalto University at OtaNano Micronova Nanofabrication Centre. 
${ }^{1}$ K.S. Novoselov, A.K. Geim, S.V. Morozov, D. Jiang, Y. Zhang, S.V. Dubonos, I.V. Grigorieva, and A.A. Firsov, Science 306, 666 (2004).

${ }^{2}$ M. Chhowalla, H.S. Shin, G. Eda, L.-J. Li, K.P. Loh, and H. Zhang, Nat. Chem. 5, 263 (2013).

${ }^{3}$ M. Samadi, N. Sarikhani, M. Zirak, H. Zhang, H.-L. Zhang, and A.Z. Moshfegh, Nanoscale Horizons 3, 90 (2018).

${ }^{4}$ M.J. Allen, V.C. Tung, and R.B. Kaner, Chem. Rev. 110, 132 (2010).

${ }^{5}$ F. Schwierz, J. Pezoldt, and R. Granzner, Nanoscale 7, 8261 (2015).

${ }^{6}$ N. Huo and G. Konstantatos, Adv. Mater. available online at http://dx.doi.org/10.1002/adma.201801164.

${ }^{7}$ J. Shi, M. Hong, Z. Zhang, Q. Ji, and Y. Zhang, Coord. Chem. Rev. 376, 1 (2018).

${ }^{8}$ A.K. Geim and I. V Grigorieva, Nature 499, 419 (2013).

${ }^{9}$ S.Z. Butler, S.M. Hollen, L. Cao, Y. Cui, J.A. Gupta, H.R. Gutiérrez, T.F. Heinz, S.S. Hong, J. Huang, A.F. Ismach, E. Johnston-Halperin, M. Kuno, V.V. Plashnitsa, R.D. Robinson, R.S. Ruoff, S. Salahuddin, J. Shan, L. Shi, M.G. Spencer, M. Terrones, W. Windl, and J.E. Goldberger, ACS Nano 7, 2898 (2013).

${ }^{10}$ G.H. Han, D.L. Duong, D.H. Keum, S.J. Yun, and Y.H. Lee, Chem. Rev. 118, 6297 (2018).

${ }^{11}$ C. Yan, C. Gong, P. Wangyang, J. Chu, K. Hu, C. Li, X. Wang, X. Du, T. Zhai, Y. Li, and J. Xiong, Adv. Funct. Mater. 28, 1803305 (2018).

12 K.F. Mak, C. Lee, J. Hone, J. Shan, and T.F. Heinz, Phys. Rev. Lett. 105, 136805 (2010).

${ }^{13}$ W. Zhao, Z. Ghorannevis, L. Chu, M. Toh, C. Kloc, P.-H. Tan, and G. Eda, ACS Nano 7, 791 (2013).

${ }^{14}$ S. Presolski and M. Pumera, Mater. Today 19, 140 (2015). 
${ }^{15}$ A.M. Dadgar, D. Scullion, K. Kang, D. Esposito, E.H. Yang, I.P. Herman, M.A.

Pimenta, E.-J.G. Santos, and A.N. Pasupathy, Chem. Mater. 30, 5148 (2018).

${ }^{16}$ Y. Wang, C. Cong, W. Yang, J. Shang, N. Peimyoo, Y. Chen, J. Kang, J. Wang, W. Huang, and T. Yu, Nano Res. 8, 2562 (2015).

${ }^{17}$ H. Wang, H. Yuan, S.S. Hong, Y. Li, and Y. Cui, Chem. Soc. Rev. 44, 2664 (2015).

${ }^{18}$ H.M.W. Khalil, M.F. Khan, J. Eom, and H. Noh, ACS Appl. Mater. Interfaces 7, 23589 (2015).

${ }^{19}$ D.M. Hamann, E.C. Hadland, and D.C. Johnson, Semicond. Sci. Technol. 32, 093004 (2017).

${ }^{20}$ H. Jiang, J. Phys. Chem. C 116, 7664 (2012).

${ }^{21}$ G. Wang, A. Chernikov, M.M. Glazov, T.F. Heinz, X. Marie, T. Amand, and B. Urbaszek, Rev. Mod. Phys. 90, 021001 (2018).

${ }^{22}$ X. Liu, J. Hu, C. Yue, N.D. Fera, Y. Ling, Z. Mao, and J. Wei, ACS Nano 8, 10396 (2014).

${ }^{23}$ K. Kang, S. Xie, L. Huang, Y. Han, P.Y. Huang, K.F. Mak, C.-J. Kim, D. Muller, and J. Park, Nature 520, 656 (2015).

${ }^{24}$ C. Xie, C. Mak, X. Tao, and F. Yan, Adv. Funct. Mater. 27, 1603886 (2017).

${ }^{25}$ X. Zong, J. Han, G. Ma, H. Yan, G. Wu, and C. Li, J. Phys. Chem. C 115, 12202 (2011).

${ }^{26}$ Y. Sang, Z. Zhao, M. Zhao, P. Hao, Y. Leng, and H. Liu, Adv. Mater. 27, 363 (2015).

${ }^{27}$ D. Voiry, H. Yamaguchi, J. Li, R. Silva, D.C.B. Alves, T. Fujita, M. Chen, T. Asefa, V.B. Shenoy, G. Eda, and M. Chhowalla, Nat. Mater. 12, 850 (2013).

${ }^{28}$ A. Khalil, Q. Liu, Q. He, T. Xiang, D. Liu, C. Wang, Q. Fang, and L. Song, RSC Adv. 6, 48788 (2016).

${ }^{29}$ M. Bosi, RSC Adv. 8, 75500 (2015).

${ }^{30}$ S.H. Choi, B. Stephen, J.-H. Park, J.S. Lee, S.M. Kim, W. Yang, and K.K. Kim, Sci. Rep. 7, 1983 (2017). 
${ }^{31}$ J. Park, W. Lee, T. Choi, S.-H. Hwang, J.M. Myoung, J.-H. Jung, S.-H. Kim, and H. Kim, Nanoscale 7, 1308 (2015).

${ }^{32}$ V.O. Gordo, M.A.G. Balanta, Y.G. Gobato, F.S. Covre, H.V.A. Galeti, F. Iikawa, O.D.D. Couto Jr, F. Qu, M. Henini, D.W. Hewak, and C.C. Huang, Nanoscale 10, 4807 (2018).

${ }^{33}$ Y. Zhang, Y. Zhang, Q. Ji, J. Ju, H. Yuan, J. Shi, T. Gao, D. Ma, M. Liu, Y. Chen, X. Song, H.Y. Hwang, Y. Cui, and Z. Liu, ACS Nano 7, 8963 (2013).

${ }^{34}$ C. Cong, J. Shang, X. Wu, B. Cao, N. Peimyoo, C. Qiu, L. Sun, and T. Yu, Adv. Opt. Mater. 2, 131 (2014).

${ }^{35}$ K. Bogaert, S. Liu, J. Chesin, D. Titow, S. Gradecak, and S. Garaj, Nano Lett. 16, 5129 (2016).

${ }^{36}$ J.-G. Song, J. Park, W. Lee, T. Choi, H. Jung, C.W. Lee, S.-H. Wang, J.M. Myoung, J.H. Jung, S.-H. Kim, C. Lansalot-Matras, and H. Kim, ACS Nano 7, 11333 (2013).

37 Y. Jung, J. Shen, Y. Liu, J.M. Woods, Y. Sun, and J.J. Cha, Nano Lett. 14, 6842 (2014).

${ }^{38}$ S.M. George, Chem. Rev. 110, 111 (2010).

${ }^{39}$ R.W. Johnson, A. Hultqvist, and S.F. Bent, Mater. Today 17, 236 (2014).

${ }^{40}$ M. Leskelä, J. Niinistö, and M. Ritala, in Comprehensive Materials Processing, vol 4, edited by S. Hashmi and D. Cameron (Elsevier, Amsterdam, Netherlands 2014), pp. 101123.

${ }^{41}$ M. Ritala and J. Niinistö, ECS Trans. 25, 641 (2009).

${ }^{42}$ W. Hao, C. Marichy, and C. Journet, 2D Mater. 6, 012001 (2019).

${ }^{43}$ A. Delabie, M. Caymax, B. Groven, M. Heyne, K. Haesevoets, J. Meersschaut, T. Nuytten, H. Bender, T. Conard, P. Verdonck, S. Van Elshocht, S. De Gendt, M. Heyns, K. Barla, I. Radu, and A. Thean, Chem. Commun. 51, 15692 (2015).

${ }^{44}$ B. Groven, M. Heyne, A.N. Mehta, H. Bender, T. Nuytten, J. Meersschaut, T. Conard, P. Verdonck, S. Van Elshocht, W. Vandervorst, S. De Gendt, M. Heyns, I. Radu, M. 
Caymax, and A. Delabie, Chem. Mater. 29, 2927 (2017).

${ }^{45}$ B. Groven, A.N. Mehta, H. Bender, Q. Smets, J. Meersschaut, A. Franquet, T. Conard, T. Nuytten, P. Verdonck, W. Vandervorst, M. Heyns, I. Radu, M. Caymax, and A.

Delabie, J. Vac. Sci. Technol. A 36, 01 A105 (2018).

${ }^{46}$ B. Groven, A.N. Mehta, H. Bender, J. Meersschaut, T. Nuytten, P. Verdonck, T. Conard, Q. Smets, T. Schram, B. Schoenaers, A. Stesmans, V. Afanas'ev, W. Vandervorst, M. Heyns, M. Caymax, I. Radu, and A. Delabie, Chem. Mater. 30, 7648 (2018).

${ }^{47}$ T.W. Scharf, S. V. Prasad, M.T. Dugger, P.G. Kotula, R.S. Goeke, and R.K. Grubbs, Acta Mater. 54, 4731 (2006).

${ }^{48}$ T.W. Scharf, S.V. Prasad, T.M. Mayer, R.S. Goeke, and M.T. Dugger, J. Mater. Res. 19, 3443 (2004).

${ }^{49}$ T.W. Scharf, D.R. Diercks, B.P. Gorman, S. V. Prasad, and M.T. Dugger, Tribol. Trans. 52, 284 (2009).

${ }^{50}$ D.K. Nandi, U.K. Sen, A. Dhara, S. Mitra, and S.K. Sarkar, RSC Adv. 6, 38024 (2016).

${ }^{51}$ Y. Sun, Z. Chai, X. Lu, and J. Lu, Tribol. Int. 114, 478 (2017).

${ }^{52}$ S. Yeo, D.K. Nandi, R. Rahul, T.H. Kim, B. Shong, Y. Jang, J.-S. Bae, J.W. Han, S.-H. Kim, and H. Kim, Appl. Surf. Sci. 459, 596 (2018).

${ }^{53}$ R. Browning, P. Plachinda, P. Padigi, R. Solanki, and S. Rouvimov, Nanoscale 8, 2143 (2015).

${ }^{54}$ T. Suntola, Thin Solid Films 216, 84 (1992).

${ }^{55}$ M.H. Chisholm and J.D. Martin, in Inorganic Syntheses, vol 29, edited by R.N. Grimes (John Wiley \& Sons, Hoboken, NJ, 1992), pp. 137-140.

${ }^{56}$ R.A. Waldo, in Microbeam Analysis, edited by D.E. Newbury (San Francisco Press, San Francisco, 1988), pp. 310-314.

${ }^{57}$ CRC Handbook of Chemistry and Physics, 98th ed. online (CRC Press, Boca Raton, 
FL, 2017-2018) available online at http://hbcpnetbase.com (accessed May 7, 2018)

${ }^{58}$ See supplementary material at [URL will be inserted by AIP Publishing] for additional XRD, Raman, AFM, and UV-VIS data of as-deposited and annealed tungstens sulfide films.

${ }^{59}$ J. Xu, J. Zhang, W. Zhang, and C.-S. Lee, Adv. Energy Mater. 7, 1700571 (2017).

${ }^{60}$ C.L. Dezelah, O.M. El-Kadri, I.M. Szilágyi, J.M. Campbell, K. Arstila, L. Niinistö, and C.H. Winter, J. Am. Chem. Soc. 128, 9638 (2006).

${ }^{61}$ C.L. Dezelah, O.M. El-Kadri, K. Kukli, K. Arstila, R.J. Baird, J. Lu, L. Niinistö, and C.H. Winter, J. Mater. Chem. 17, 1109 (2007).

${ }^{62}$ M. Mattinen, P.J. King, L. Khriachtchev, K. Meinander, J.T. Gibbon, V.R. Dhanak, J. Räisänen, M. Ritala, and M. Leskelä, Small 14, 1800547 (2018).

${ }^{63}$ M.H. Heyne, J.-F. de Marneffe, T. Nuytten, J. Meersschaut, T. Conard, M. Caymax, I. Radu, A. Delabie, E.C. Neyts, and S. De Gendt, J. Mater. Chem. C 6, 4122 (2018).

${ }^{64}$ J. Gao, B. Li, J. Tan, P. Chow, T.-M. Lu, and N. Koratkar, ACS Nano 10, 2628 (2016).

${ }^{65}$ G. Mirabelli, C. McGeough, M. Schmidt, E.K. McCarthy, S. Monaghan, I.M. Povey, M. McCarthy, F. Gity, R. Nagle, G. Hughes, A. Cafolla, P.K. Hurley, and R. Duffy, J. Appl. Phys. 120, 125102 (2016).

${ }^{66}$ A. Berkdemir, H.R. Gutiérrez, A.R. Botello-Méndez, N. Perea-López, A.L. Elías, C.-I. Chia, B. Wang, V.H. Crespi, F. López-Urías, J.-C. Charlier, H. Terrones, and M. Terrones, Sci. Rep. 3, 1755 (2013).

${ }^{67}$ M.M. Alsabban, S. Min, M.N. Hedhili, J. Ming, L.-J. Li, and K.-W. Huang, ECS J. Solid State Sci. Technol. 5, Q3067 (2016).

${ }^{68}$ I. Martin-Litas, P. Vinatier, A. Levasseur, J.C. Dupin, D. Gonbeau, and F. Weill, Thin Solid Films 416, 1 (2002).

${ }^{69}$ D.J. Morgan, Surf. Sci. Spectra 25, 014002 (2018).

${ }^{70}$ T.H. Choudhury, H. Simchi, R. Boichot, M. Chubarov, S.E. Mohney, and J.M. Redwing, Cryst. Growth Des. 18, 4357 (2018). 
${ }^{71}$ L. Su, Y. Yu, L. Cao, and Y. Zhang, Nano Res. 8, 2686 (2015).

${ }^{72}$ H.-S. Liu, T. Yang, Y. Tatsumi, Y. Zhang, B. Dong, H. Guo, Z. Zhang, Y. Kumamoto, M.-Y. Li, L.-J. Li, R. Saito, and S. Kawata, Sci. Rep. 8, 11398 (2018).

${ }^{73}$ X. Zhang, X.-F. Qiao, W. Shi, J.-B. Wu, D.-S. Jiang, and P.-H. Tan, Chem. Soc. Rev. 44, 2757 (2015).

${ }^{74}$ W. Zhao, Z. Ghorannevis, K.K. Amara, J.R. Pang, M. Toh, X. Zhang, C. Kloc, P.H. Tan, and G. Eda, Nanoscale 5, 9677 (2013).

${ }^{75}$ R. Saito, Y. Tatsumi, S. Huang, X. Ling, and M.S. Dresselhaus, J. Phys. Condens. Matter 28, 353002 (2016).

${ }^{76}$ J.T. Mlack, P.M. Das, G. Danda, Y.-C. Chou, C.H. Naylor, Z. Lin, N.P. López, T. Zhang, M. Terrones, A.T.C. Johnson, and M. Drndić, Sci. Rep. 7, 43037 (2017).

${ }^{77}$ B. Chakraborty, A. Bera, D.V.S. Muthu, S. Bhowmick, U. V Waghmare, and A.K. Sood, Phys. Rev. B 85, 161403(R) (2012).

${ }^{78}$ W. Zeng, L.-P. Feng, J. Su, H.-X. Pan, and Z.-T. Liu, J. Alloys Compd. 745, 834 (2018). 
Table I. Elemental composition of an as-deposited tungsten sulfide film averaged over the $40 \mathrm{~nm}$ film thickness and on the surface as measured by ToF-ERDA and XPS, respectively. The film was deposited on silicon at $150{ }^{\circ} \mathrm{C}$ using 500 cycles.

\begin{tabular}{ccc}
\hline \hline Element & $\begin{array}{c}\text { Average (at-\%) } \\
\text { ToF-ERDA }\end{array}$ & $\begin{array}{c}\text { Surface (at-\%) } \\
\text { XPS }\end{array}$ \\
\hline $\mathrm{W}$ & $37.9 \pm 0.2$ & 24.7 \\
$\mathrm{~S}$ & $42.0 \pm 0.7$ & 21.8 \\
$\mathrm{~S} / \mathrm{W}$ & $1.11 \pm 0.02$ & 0.88 \\
$\mathrm{C}$ & $7.1 \pm 0.4$ & 29.5 \\
$\mathrm{~N}$ & $3.3 \pm 0.3$ & 1.9 \\
$\mathrm{O}$ & $3.8 \pm 0.3$ & 22.1 \\
$\mathrm{H}$ & $5.8 \pm 1.2$ & Not detectable \\
\hline \hline
\end{tabular}

Table II. Elemental surface composition of tungsten sulfide films as-deposited and after annealing as analyzed by XPS. The films were deposited on silicon at $150{ }^{\circ} \mathrm{C}$ using 100 cycles and the annealing was done in $\mathrm{H}_{2} \mathrm{~S} / \mathrm{N}_{2}$ atmosphere for $1 \mathrm{~h}$.

\begin{tabular}{ccccc}
\hline \hline Element & $\begin{array}{r}\text { As-deposited } \\
(\text { at-\% })\end{array}$ & $\begin{array}{c}300{ }^{\circ} \mathrm{C} \\
(\text { at-\%) }\end{array}$ & $\begin{array}{c}400{ }^{\circ} \mathrm{C} \\
(\text { at-\% })\end{array}$ & $\begin{array}{c}500{ }^{\circ} \mathrm{C} \\
(\text { at-\% })\end{array}$ \\
\hline $\mathrm{W}$ & 22.6 & 21.4 & 16.2 & 17.1 \\
$\mathrm{~S}$ & 19.6 & 26.0 & 29.5 & 26.7 \\
$\mathrm{~S} / \mathrm{W}$ & 0.87 & 1.22 & 1.82 & 1.56 \\
$\mathrm{C}$ & 30.2 & 33.8 & 37.9 & 27.9 \\
$\mathrm{~N}$ & 3.1 & 1.8 & 1.0 & 0.8 \\
$\mathrm{O}$ & 24.6 & 16.9 & 14.2 & 27.5 \\
\hline \hline
\end{tabular}


Table III. Reported WS 2 ALD processes and characteristics of deposited films.

\begin{tabular}{|c|c|c|c|c|c|c|c|}
\hline Precursors & $\begin{array}{c}\text { Deposition } \\
\text { (annealing) } \\
\text { temperature } \\
\left({ }^{\circ}\right)\end{array}$ & $\begin{array}{l}\text { Growth } \\
\text { rate } \\
(\AA / \text { cycle })\end{array}$ & $\begin{array}{l}\text { Satura } \\
\text { tion }\end{array}$ & $\begin{array}{l}\text { Thickness } \\
\text { (nm) }\end{array}$ & $\begin{array}{l}\text { Grain } \\
\text { size } \\
(\mathrm{nm})\end{array}$ & $\begin{array}{l}\mathrm{S} / \mathrm{W} \\
\text { ratio }\end{array}$ & Ref. \\
\hline $\begin{array}{c}\mathrm{W}_{2}\left(\mathrm{NMe}_{2}\right)_{6} \\
+\mathrm{H}_{2} \mathrm{~S}\end{array}$ & $150(400)$ & $0.8-0.9$ & yes & $\sim 2-10$ & $\sim 3-10$ & 1.8 & $\begin{array}{l}\text { This } \\
\text { work }\end{array}$ \\
\hline $\mathrm{WF}_{6}+\mathrm{H}_{2} \mathrm{~S}^{\mathrm{b}}$ & $300-350$ & $\sim 1$ & $-{ }^{\mathrm{a}}$ & $10-300$ & $5-100$ & - & 47,49 \\
\hline \multirow[t]{2}{*}{$\begin{array}{c}\mathrm{WF}_{6}+\mathrm{H}_{2} \\
\text { plasma }+ \\
\mathrm{H}_{2} \mathrm{~S}\end{array}$} & $250-450$ & $\sim 0.2$ & yes & $\sim 1-3$ & $\sim 10$ & $\begin{array}{c}1.8 \pm 0 \\
1\end{array}$ & $43-45$ \\
\hline & 450 & $\sim 0.2$ & yes & $<1-5$ & $\begin{array}{l}\text { up to } \\
200\end{array}$ & $\begin{array}{c}1.8 \pm 0 \\
1\end{array}$ & 46 \\
\hline $\begin{array}{c}\mathrm{WCl}_{5}+ \\
\mathrm{H}_{2} \mathrm{~S}\end{array}$ & 390 & 1.25 & $-{ }^{\mathrm{a}}$ & $<5$ & cryst. $^{\mathrm{c}}$ & - & 53 \\
\hline \multirow[t]{2}{*}{$\begin{array}{c}\mathrm{W}(\mathrm{CO})_{6}+ \\
\mathrm{H}_{2} \mathrm{~S}\end{array}$} & $165-205$ & $\sim 0.2$ & yes & $20-40$ & amorph & 2.05 & 50 \\
\hline & 400 & 3.6 & $-{ }^{\mathrm{a}}$ & 175 & $\sim 5$ & - & 51 \\
\hline $\begin{array}{c}\mathrm{W}(\mathrm{CO})_{6}+ \\
\mathrm{H}_{2} \mathrm{~S} \text { plasma }\end{array}$ & 350 & $\sim 1$ & yes & $3-20$ & $3-7$ & 1.94 & 52 \\
\hline
\end{tabular}

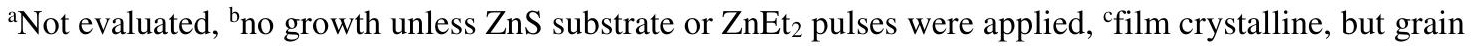
size not indicated. 
FIG. 1. TGA of $\mathrm{W}_{2}\left(\mathrm{NMe}_{2}\right)_{6}$ (structure shown as an inset) under $\mathrm{N}_{2}$ atmosphere.

FIG. 2. Growth rate and $\mathrm{S} / \mathrm{W}$ ratio versus a) $\mathrm{W}_{2}\left(\mathrm{NMe}_{2}\right)_{6}$ and b) $\mathrm{H}_{2} \mathrm{~S}$ pulse length. c) Film thickness versus number of ALD cycles. d) Growth rate and S/W ratio versus deposition temperature. Film thicknesses were measured by EDS (a,b,d) or XRR (c). S/W ratio was measured by EDS. Unless otherwise noted, the films were deposited on native oxide covered silicon substrates at $150{ }^{\circ} \mathrm{C}$ using 500 cycles with $1 \mathrm{~s} \mathrm{~W} 2\left(\mathrm{NMe}_{2}\right)_{6}$ and 2 (a) or $4 \mathrm{~s}$ (c,d) $\mathrm{H}_{2} \mathrm{~S}$ pulses separated by $3(\mathrm{a}, \mathrm{b})$ or $2 \mathrm{~s}(\mathrm{c}, \mathrm{d}) \mathrm{N}_{2}$ purges. The line in c) represents a linear fit to the data, whereas the other lines are only to guide the eye.

FIG. 3. a) Raman spectra and b) grazing incidence X-ray diffractograms of tungsten sulfide films as-deposited and after annealing at different temperatures. The films were deposited on silicon at $150{ }^{\circ} \mathrm{C}$ using 100 cycles and the annealing was done in $\mathrm{H}_{2} \mathrm{~S} / \mathrm{N}_{2}$ atmosphere for $1 \mathrm{~h}$. The Raman and XRD peaks of $\mathrm{WS}_{2}$ were indexed according to Ref.66 and Powder Diffraction File (PDF) 8-0237, respectively.

FIG. 4. X-ray photoelectron spectra of a) W $4 \mathrm{f}$ and b) S 2p regions. The films were deposited on silicon at $150{ }^{\circ} \mathrm{C}$ using 100 cycles. The annealing was done in $\mathrm{H}_{2} \mathrm{~S} / \mathrm{N}_{2}$ atmosphere for $1 \mathrm{~h}$.

FIG. 5. AFM images and roughness $\left(\mathrm{R}_{\mathrm{q}}\right)$ values of tungsten sulfide films as-deposited and after annealing at different temperatures. Note the different height scale for the sample annealed at $500{ }^{\circ} \mathrm{C}$. The films were deposited on silicon at $150{ }^{\circ} \mathrm{C}$ using 100 cycles and the annealing was done in $\mathrm{H}_{2} \mathrm{~S} / \mathrm{N}_{2}$ atmosphere for $1 \mathrm{~h}$.

FIG. 6. a) Thickness of annealed tungsten sulfide films, where the red line represents linear fit to the data and arrow shows the estimated thickness of the 10 cycle film assuming linear growth. b) AFM images of annealed tungsten sulfide films. The films were deposited at $150{ }^{\circ} \mathrm{C}$ and annealed at $400{ }^{\circ} \mathrm{C}$ for $1 \mathrm{~h}$.

FIG. 7. a) Raman spectra of $\mathrm{WS}_{2}$ films of different thicknesses after annealing at $400{ }^{\circ} \mathrm{C}$. b) Raman spectrum of a 25 cycle $\mathrm{WS}_{2}$ film annealed at $400{ }^{\circ} \mathrm{C}$ showing the modes fitted between 300 and $450 \mathrm{~cm}^{-1}$. c) Fitted positions of the $A_{1 g}, E_{2 g}^{1}$, and 2LA(M) modes. d) Frequency difference $A_{1 g}-E^{1}{ }_{2 g}$. Open and crossed symbols in c) and d) represent 
literature values from Berkdemir et al. (CVD-grown flakes) ${ }^{66}$ and Zhao et al. (exfoliated flakes), ${ }^{74}$ respectively.

FIG. 8. a) Low and b) high magnification HAADF-STEM images of a 50 cycle $\mathrm{WS}_{2}$ film annealed at $400{ }^{\circ} \mathrm{C}$. c) (002) (dashed) and (100) or (101) planes (solid) highlighted in the high magnification image along with the estimated interplane distances. 